How to cite this article:

Rahmawati, D., \& Rahadi, R. A. (2019). An appropriate business strategy for small medium entreprises: A case study of piksel Indonesia. Malaysian Management Journal, Vol. 23(December), 99-114.

\title{
AN APPROPRIATE BUSINESS STRATEGY FOR SMALL MEDIUM ENTREPRISES: A CASE STUDY OF PIKSEL INDONESIA
}

\author{
DWI RAHMAWATI* \\ RADEN ASWIN RAHADI \\ School of Business Management \\ Institut Teknologi Bandung, Indonesia
}

*Corresponding author:dwi_rahmawati@sbm-itb.ac.id

\begin{abstract}
The aim of the study is to establish the most appropriate business strategy for Piksel Indonesia which is a creative company focusing on technology and fashion designs, resulting from the batik consumption preferences while planning to use batik products. Data from 338 respondents were randomly collected from several cities in Indonesia. The first section deals with the demographic background of the respondents, and the remaining of the questions deal with the respondents' impulse towards batik products. The survey results show differences in previous studies. The first difference is the source of information about batik products obtained by the customer. Secondly, the study by the researchers builds on the consumer's tastes about the batik style and the results are 54.6 percent. Integrated cost leadership/ differentiation is Piksel Indonesia's best business strategy. For Batik Fractal, their batik products brand, low cost was achieved by employing their vendor to produce the product from the minimum overhead. The production flow begins with the order of the customer that the pattern, colour, material and size chart have been determined. JBatik, which is a parametric software to make a new and distinguish batik pattern established by Piksel Indonesia, has no direct competitors at present. As with Batik Fractal, integrated cost management/differentiation strategy is the best strategy.
\end{abstract}


Keywords: Batik industry, business strategy, business level strategy, small medium entreprise.

Received: $26 / 11 / 2018$

Revised: 10/2/2020

Accepted: 10/3/2020

\section{Introduction}

Indonesia has an extensive arts and cultures heterogeneity including batik (Suwandari et al., 2017). Batik is one of the textiles representing the Indonesian standard of printed textile as well as the printed design. An alliance of two Javanese words, 'amba', meaning write and 'titik', meaning point, is used to mean the word batik. Since batik was recognised by the UN Agency for Education, Science and Culture or UNESCO as a world heritage site, on October 2nd 2009 batik was established as the main piece of human oral and intangible heritage. Many Indonesians chose batik for their everyday apparel. The demands of other batik products have increased in the fashion industry. Today, batik manufacturers offer a wide range of different types of batik products including accessories, bags and wallets. There are many preferences for Indonesian batik quality, pattern, colour, and model (Rahmawati, Rahadi \& Damayanti, 2018). Recently, Batik industry has developed rapidly, and its potential is enormous in the future. There were 47,755 Batik SMEs in 2015, with more than 200,000 jobs contributed by this industry, following the remarks by the Director General of SMEs and the Ministry of Industry of the Republic of Indonesia (Pinasti \& Adawiyah, 2016).

Nugroho and Andadari (2014) stated that the growth of small and mediumsized entreprises has encouraged the Indonesia's economy to grow. The SMI industry has spread across 101 centres across Indonesia. Director-General of Small and Medium Industries (SMI) stated that Indonesia has been the main player on the global markets. The statement confirmed that the export of batik and other goods by 2017 equaivalent to that of the US with 58.46 million, Japan, and Europe being the main destination countries. Piksel Indonesia is a technology-driven company in the batik industry that produces batik. Piksel Indonesia is the sole company which invented the batik design software known as JBatik and produced the batik product known as Batik Fractal as its batik brand. The software was developed by Nancy Margried, Yun Hariadi and Muhamad Lukman in their research on traditional batik patterns as well as the relation to fractal in mathematical concept. More than 300 traditional Batik patterns from throughout Indonesia have been researched and the fractal mathematical elements collected in 2007 were examined. Research shows that batik has an element of mathematics and can be modelled on 
fractals. The modeling of the new Batik variant of the fractal mathematical formula was later called, Batik Fractal. It consists of two main products.

\section{jBatik}

jBatik is a parametric software designed by Piksel Indonesia to produce a variety of batik patterns. Batik Fractal is the brand that introduces batik cloth products from Piksel Indonesia whose designs are made with jBatik. The programming language of this software is Java, which works with the generative system. The input is an image-generating fractal format of this software.

\section{Batik Fractal}

Batik Fractal is the brand batik that utilises the software jBatik to develop its fractal formulation. The Piksel Indonesia designer is manufactured by Batik Fractal in-house with seasonal design planning. In Solo, Yogyakarta, Pekalongan, Cirebon and Bandung the production of is made by the batik artisans. In Indonesia, Batik Fractal products are all manufactured by artisans with 90 percent to 100 percent Indonesian materials.

\section{Business Issue}

In line with the robust expansion of the batik industry, some general issues in the industry were managed by Piksel Indonesia. On the basis of the industry observation, two clues (problems) had been identified in the Indonesian batik industry. Firstly, there is little difference in products because in the region, artisans frequently use standard patterns and similar designs. The second is that the middle and shop-owners rather than the artisans who significantly affect the portion of the profits of batik companies. Piksel Indonesia needs

a number of programmes to handle these problems. They help artisans to boost their revenues in two ways; (1) trains crafted artisans in their patent technology called jBatik to differentiate between their own designs and (2) Piksel Indonesia helps the market artisans' products under their collective brand called Batik Fractal. Their sales are dominated by the product of uniforms. The details are presented in the following (Table 1).

A strategy is a bundle of commitments and actions aimed at exploiting the core competencies of a company and gaining competitive advantage (Michael, Ireland, Robert \& Hoskisson, 2011). Piksel Indonesia has a conventional strategy to increase its sales through direct marketing by directly approaching customers. However, the market for batik products is growing 
and its strategies need to be developed. The internal and external analysis form the SWOT variables of the company. Furthermore, the market research is carried out to resolve such problems and to develop a more comprehensive new strategy for Piksel Indonesia.

Table 1

Piksel Indonesia's Sales Percentage

\begin{tabular}{lcc}
\hline Product & 2016 & 2017 \\
\hline Uniforms & $68.28 \%$ & $91.29 \%$ \\
Software & $8.71 \%$ & $2.52 \%$ \\
Retail product & $9.63 \%$ & $0.59 \%$ \\
Design fee & $0.55 \%$ & $5.60 \%$ \\
Corporate merchandise & $12.83 \%$ & $0 \%$ \\
\hline Total & $100 \%$ & $100 \%$ \\
\hline
\end{tabular}

Source: Piksel Indonesia (2018).

\section{Literature Review}

\section{External Environment}

The external environment consists of a general analysis of the industry and the environment of competitors. The broader environment consists of dimensions that influence the industry and its company, and the industry itself reflects the factors that have direct effects on the company, its competitive actions and responses (Michael al., 2011). A list of opportunities and threats from one industry or company was made based on the analysis of the external environment (Kotler \& Keller, 2016).

\section{Internal Environment}

According to Kotler and Keller (2016), and O'Dwyer et al. (2009), a list of company strength and weaknesses will result from the internal environment that reflects the company's resources and how these can develop core skills and competitive advantages, which are important for SMEs. This is because they can be created from the small and medium-sized network operations. In fact, resources and capabilities are consistently valuable, and the value created by the company can draw up a series of competitive advantages strategies and activities (Michael al., 2011; Nuryakin, 2018). 


\section{Variables of SWOT}

SWOT analysis is a whole appraisal that involves four areas of a company namely, strength (S), internal information weaknesses (W) such as environmental analysis, and environmental opportunity $(\mathrm{O})$ and external threats (T) (Gurel \& Tat, 2017; Kapoor \& Kaur, 2017). This is one of the ways in which a more detailed strategy planning initiative has been developed (Schmal, Karen \& Chen, 2017). Moreover, many studies have shown that in assessing the company's resources, capabilities and market situation, this SWOT approach is the most frequent tool used by the managers (Madsen, 2016).

It is possible to conduct the TOWS Matrix strategy through the SWOT analysis of the company. Wihrich's TOWS Matrix is established as an approach to expanding SWOT analysis as shared in the seminal paper (Wiehrich, 1982). The intersection between strength and opportunities identified the strengths, according to Schmal et al. (2017) and Kim (2016), which can be used for capturing opportunities outside the company, and the weakness and the threat can mitigate the threat in the weakness of the company. The following figure summarises some strategies under the TOWS analysis.

Table 2

TOWS Matrix (Kapoor \& Kaur, 2017)

\begin{tabular}{lll}
\hline & \multicolumn{1}{c}{ Strength } & \multicolumn{1}{c}{ Weakness } \\
\hline Opportunity & $\begin{array}{l}\text { Maxi-Maxi } \\
\text { Comprises the internal strength } \\
\text { and the opportunities available } \\
\text { which makes this the most } \\
\text { desirable strategy. }\end{array}$ & $\begin{array}{l}\text { Mini-Maxi } \\
\text { Based on the cultivation of } \\
\text { the company by utilizing the } \\
\text { opportunities in order to cope with } \\
\text { its weaknesses. }\end{array}$ \\
$\begin{array}{l}\text { Maxi-Mini } \\
\text { Threats }\end{array}$ & $\begin{array}{l}\text { Mini-Mini } \\
\text { The purpose of this strategy is } \\
\text { strengths to tackle its current } \\
\text { threats to maximise the first } \\
\text { ones and to minimise the last } \\
\text { ones. }\end{array}$ & weaknesses. \\
&
\end{tabular}

\section{Customers' Preferences on Batik Product}

The empathy map of the consumer in Nurfikriyadi's (2016) study shows that casually cheap batik is the most preferred among respondents or batik customers, which aligned with the study by Sabijono (2013) on the customer's most significant value. Yet the most important preferences in buying batik 
is the design as pointed out by Pesol, Mustapha, Ismail and Yusoff (2016). The research reveals that customers favour the production or seller to see great promotions. Furthermore, they tend to touch and look at the product to see if they will buy it. Finally, customers take the recommendation of their colleagues strongly before buying batik instead of doing some research on the product.

\section{Methodology}

A mixed methods design that aims to counter the business issues is used in this research which cannot be fulfilled by solely qualitative or quantitative research (Sekaran \& Bougie, 2016). Moreover, the primary data would be utilised as the main analysis whilst those input collected from the interviews with particular parties were part of the qualitative approach and the quantitative data were gathered through a market research using questionnaires.

\section{Internal Interview}

The main method is to use profound interviews and observational research. The in-depth interview was held by conducting a "one-on-one" interview with Batik Fractal's key respondents and the internal party. The observations took place on the basis of two months of internship experience. The researchers found the main problem of the business following the observation. The problem was examined and a possible solution based on the literature review and problem-solving activities were addressed.

\section{Market Research}

To collect information on the primary data and the actual market conditions, a number of systematic activities was carried out to develop, collect, analyse, and report data (Kotler \& Armstrong 2012). In this case, the researcher conducted a market survey by applying a questionnaire to discover the customers' preference for batik products. By utilising the questionnaire, it enabled author to collect a huge number or quantitative data to be managed personally or distributed electronically to the possible respondents (Sekaran $\&$ Bougie, 2016). There are advantageous of employing the questionnaire as a method, such as structured formats, simple and straightforward for the respondents, low-cost and fast (Walliman, 2011). The questionnaire was modified based on a similar survey on the batik industry by Nurfikriyadi (2017). 
Unrestricted probability sampling employed to counter the business issues in this research, by that means each element in the population is possible to a known and equal chance to be the subject (Sekaran \& Bougie, 2016). A total of 338 respondents from different cities in Indonesia were selected. The questionnaire consists of 21 questions which comprise items related to the batik products and the customers' preference. The descriptive analysis was used to validate and test the reliability of the data. Statistical descriptive analysis is a quantifying method of parametric numeric data such as the centre, the width of the spread, the central trend point, the mode, the median, and the means (Walliman, 2017).

\section{Results}

\section{The Position of the Company}

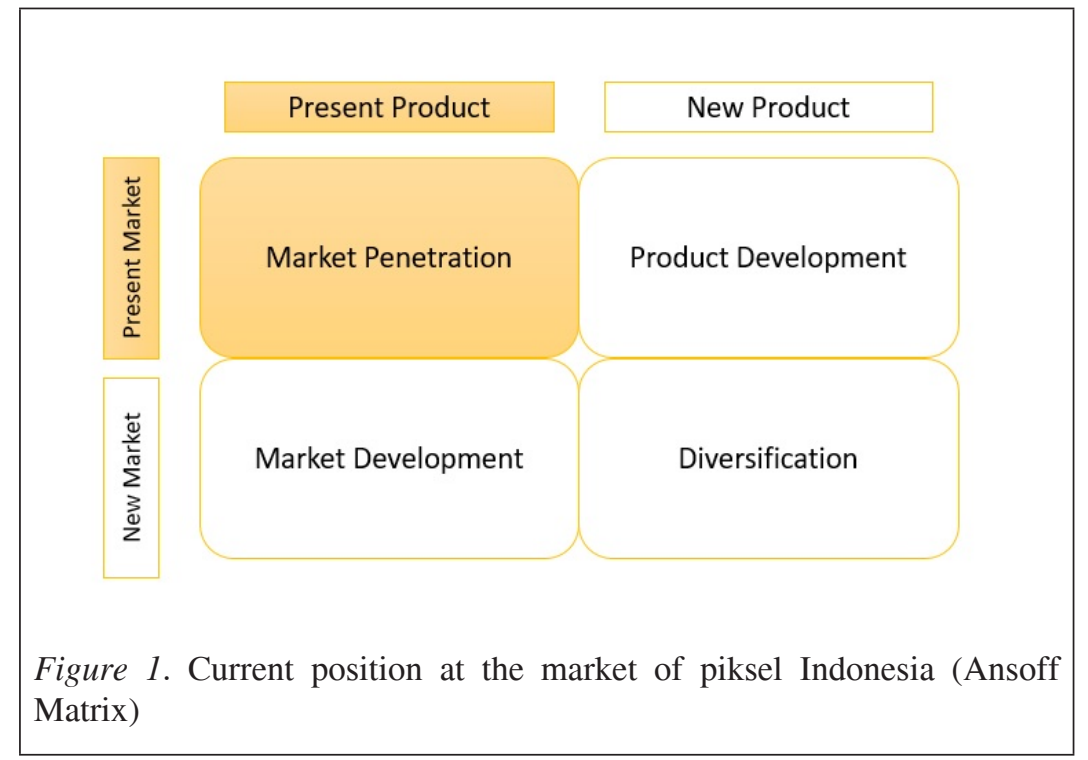

As shown in Figure 1, the situation on the market remains that Piksel Indonesia still concentrates on the current market of retailers and consumer apparel. For example, by offering their software for schools and artisans to users to develop new skills they can expand their market share to a new bundle. Consider Piksel Indonesia as the only provider of software to design budget, as other renowned software providers are mainly targeted for large users or companies at a higher price. If the company uses such a strategy, 
Piksel Indonesia is possible to switch to the market development position. Moreover, Piksel Indonesia may attain its social mission to contribute to the education area and empower the artisans.

\section{SWOT Analysis}

The highest revenues of Piksel Indonesia comes from uniforms which has more frequent quantity sold and order than retail or goods products. In addition to extending the uniforms market, goods and wholesale and retail products remain the number one priority of the company strategy. Furthermore, Piksel Indonesia is better at expanding the software market because it has the competitive advantage as the only company making digital batik software, even though the sales of software have dropped when compared to 2017. JBatik nevertheless supports the craftsmen, who will logically lead their welfare in increasing productivity. Based on the interviews with Piksel Indonesia's CEO, the researchers obtained further explanation of the SWOT analysis:

\section{Strength}

i) It is capable of making product differentiation or custom designed by jBatik software. In producing particular design, consultation services are given based on the customers' requests for batik fashion products.

ii) It has some social impact in empowering local batik artisans to use the software JBatik to increase their creativity.

iii) The efficiency of production through cooperation with regional batik artisan who are very minimal on overhead and inventory costs and by using raw materials which environmentally friendly.

iii) It has good corporate management for everyday activities and good reputations among consumers which allows them to repeat orders.

iv) The task of creating batik in the educational institutions is seen as a cultural heritage which younger generation loves.

\section{Weakness}

i) It has limited capacity for business growth, particularly in the financial capacity of companies that particularly do not support yet for a wider expansion. 
ii) It comprises a small number of basic human resources handled by the CEO in certain fields of management, namely, human resources and finance.

iii) Its performance remains focused on the financial field only.

3. Opportunities

i) The domestic market is supported by citizens and has demand from the latter to use batik in the workplace.

ii) Indonesian heterogeneous culture also encourages people in the different regions to buy batik or other traditional clothings.

iii) The GDP growth increases the purchasing power of Indonesian citizens, especially in the field of clothing or fashion.

iv) Join the Company's programme to develop its business strategy in the Creative Economy Agency.

v) The option of accelerating production time using jBatik technology. Electronic word of mouth (EWOM) may be used maximumally by the company for the promotion and marketing of its products.

vi) The global potential market is increasingly aligned with the tourism industry growth, which is attracting many foreigners with batik because of its unique patterns and background.

vii) Be the only company providing a distinct market in Indonesia for affordable batik patternmaker software.

4. Threats

i) The emergence of competitors with a similar product as a result of domestic and global demand growth.

ii) Volatility in the exchange rates between the US and Rupiah which could affect foreign customer transactions.

\section{TOWS Matrix Analysis}

The SWOT analysis enables further explanation on the two possible conditions as shown in Table 3, that is, to form the TOWS matrix analysis, and to determine Piksel Indonesia's most appropriate strategies to achieve this objective: 
Table 3

Piksel Indonesia’s TOWS Matrix Analysis

\begin{tabular}{ll}
\hline Strength & Weakness \\
\hline
\end{tabular}

Opportunity

1. Strengths \& Opportunities Strategy Build custom design business models for fashion products at relatively low prices compared to companies offering the same commercial service, using eWOMs that marketers in most companies use widely. By using eWOM, it will be faster to obtain information on the company so that a broader market share can be achieved considering the large potential market.

2. Strength \& Opportunities Strategy The programme allows Piksel Indonesia to market its products to educational institutions such as universities or schools, which will attract young people to prefer batiks and facilitating batik designs using jBatik software technology.

3. Strengths \& OpportunitiesStrategy: Other small and medium sized businesses are also supported by the social impact resulting from the process of collaboration with batik artisans. The social mission of Pixel Indonesia will be facilitated in particular by the Economic Creative Agency programme.

Threats

1. Strengths \& Threats Strategy: Strengthening product differentiation and cost leadership, in which the company offers batik designs that were never developed before. The use of $\mathrm{jBatik}$, can reduce production costs and the prices of fashion products ordered by consumers by using batik artisan vendors. Emphasize the social impact of the purchase of Batik Fractal by consumers.

2. Strength \& Threat Strategy Reduce the utilisation of foreign funding resources to avoid the exchange rate burden and increase the export product number to balance Indonesia's trade balance.
1. Weaknesses \& Opportunities Strategy

Piksel Indonesia is able to develop its business in almost all aspects, including financial aspects that can be used to increase its business to enhance its capabilities and productivity, by combining the six featured programmes of Economic Creative Agency.

2. Weakness \& Opportunities Strategy:

The enormous number of domestic and international potential markets also provide potential staff that are capable of filling the vacancy or are insufficient for Piksel Indonesia to develop its business.

1. Weaknesses \& Threats Strategy:

Acquire external financing to develop production of business capacity and support future innovation. Piksel Indonesia can help with this strategy to meet the customers' emerging requests. 


\section{Market Research Data}

\section{Customers' Preferences toward Purchase Decision of Batik Products}

This section pertains the preferences of customers which influence them to decide on the purchase of batik. Likert scale 1 to 10 is used to present the findings, with scale 1 showing the best factor affecting customer preferences and vice versa which is subsequently validated with a simple statistical. The ten specific considerations requested in this part are price, batik pattern, and design of the products, promotion/discount, product quality, after-sales services, easy ordering, easy payment, and shopping experience. The most important elements are shown in Table 4.

Table 4

Customers' Preferences toward Purchase Decision of Batik Products

\begin{tabular}{lcccc}
\hline Factor & $\mathrm{N}$ & Mean & Std. Deviation & Rank \\
\hline Price & 338 & 2.432 & 2.299 & 2 \\
Batik Pattern & 338 & 2.322 & 2.429 & 1 \\
Product Design & 338 & 2.515 & 2.531 & 3 \\
Promotion/discount & 338 & 2.849 & 2.454 & 5 \\
Brand & 338 & 3.879 & 2.712 & 10 \\
Product Quality & 338 & 2.607 & 2.551 & 4 \\
Service and after sales service & 338 & 3.665 & 2.746 & 9 \\
Ease of Ordering & 338 & 3.151 & 2.580 & 7 \\
Ease of Payment & 338 & 3.139 & 2.663 & 6 \\
Shopping Experience & 338 & 3.435 & 2.762 & 8 \\
\hline
\end{tabular}

The most preferable factor in buying decision is pattern of batik, the highest average of 2.322, according to the market survey results of Table 4. This fact is reflected in the fact that most respondents regard this factor as extremely important in the decision to buy. The second largest mean is price, which results in the fact that customers are highly price-sensitive in the batik industry, so that business players in this industry better pricing to capture or increase their sales carefully. The third one that is most chosen is product design, so that clients consider whether or not the product is highly distinguished from the other. Surprisingly, the brand is the customer's least factor with a minimum average of 2.712 . 
Based on this findings there are some similarities with the prior survey conducted by Nurfikriyadi (2016). The price, product design and promotion/ discount still remain to be the main buying decision. Meanwhile, the shopping experience, service and after sales service were not really considered.

\section{Customers' Preferences toward Batik Quality}

This section of the survey discusses the factors that indicate the quality of batik as rated by the customers. Five factors are applied; the design of products, patterns of batik, price, colour, and materials. This section also uses the likert scale to...,. Scale 1 indicates the best and the least preferred is indicated by Scale 5. As shown in Table 5, most respondents believe that batik pattern is the major determinant of batik quality.

Table 5

Customers' Preferences toward the Quality of Batik Products

\begin{tabular}{lcccc}
\hline Factor & $\mathrm{N}$ & Mean & Std. deviation & Rank \\
\hline Product design & 338 & 1.790 & 1.257 & 2 \\
Batik pattern & 338 & 1.781 & 1.223 & 1 \\
Price & 338 & 1.956 & 1.271 & 4 \\
Colour & 338 & 2.056 & 1.268 & 5 \\
Material & 338 & 1.888 & 1.298 & 3 \\
\hline
\end{tabular}

\section{Customers' Response toward Social Missions and Technology}

The final part of the survey addresses customers' response and the tendency towards social missions performed by Piksel Indonesia in its operations. As previously mentioned, Piksel Indonesia aims at enabling local batik workers to learn using the proprietary technology known as jBatik in Indonesia and market their products with the Batik Fractal brand. The first question in this part is the customers' response to the social mission of Piksel Indonesia. As illustrated in Table 6, approximately 86.1 percent of respondents want to be charged more for the batik products because they are interested in the social work.

The next question concerns the response of customers to the technology which Piksel Indonesia established. It is called jBatik, a software that helps users to use fractal iteration to create the batik patterns. As shown in the table below, the respondents who indicated that they wish to pay the additional cost for the technology used by the artisans of Piksel Indonesia are 65.4 percent. 
Table 6

Customers' Response toward Social Mission and Technology

\begin{tabular}{llll}
\hline Social Missions Response & Category & Frequency & Percentage \\
\hline \multirow{2}{*}{ Interest } & Yes & 291 & $86.1 \%$ \\
& No & 47 & $13.9 \%$ \\
\hline \multirow{2}{*}{ Technology Response } & Category & Frequency & Percentage \\
\hline Interest & Yes & 221 & $65.4 \%$ \\
& No & 117 & $34.6 \%$ \\
\hline
\end{tabular}

\section{Conclusions and Recommendations}

Since the majority of respondents are young generation, the company may distinguish its products based on the market segmentation divided by the age of the customers and adjust its product price. Social groups play a key role in consumer behaviour, reflecting income, education, and housing in the field of cultural and sub-cultural factors. Moreover, in the social linkage field, the word of mouth is one of the powerful tools to do the marketing strategy in order to spread the information regarding the products (Bhattacharya \& Anand, 2016). In addition, purchasing decision also depends on the personal characteristics of someone, such as age, occupation, economic situation, lifestyle, and taste (Mandey and Kawung, 2016). Therefore, both uniform or casual, and formal batik clothes are preferable for a traditional element with modern design to enable Piksel Indonesia to adopt a corporate strategy to attract the market. According to Porter's (1980) competitive strategies model is an important concept in strategic management. Salavou (2015) and Tripes, Komarkova, Pirozek \& Dvorak (2014) introduced and implemented various approaches to achieve the corporate objective by focusing on the customers' sales of products and services.

Integrated cost management/differentiation is the best business strategy for Piksel Indonesia. The strategy involves primary activities and supporting activities which enables a company to simultaneously undertake costeffective and diversified activities (Michael et al., 2011). Batik Fractal has had the low-cost of using the seller to produce its product from a minimum overall cost. The production flow is based on the order of the customer in which the batik patterns, colour, materials and dimensional charts have been determined. The first stream showed how Piksel Indonesia distinguishes every product. Product innovation may affect the company's marketing performance (Nuryakin, 2018). The manufacture will be done in the place of 
the artisans and, the company will first decide which of the artisans are ready to make the item. The process which is Flexible Manufacturing Systems is designed to decrease the low cost and product variety law inherent in traditional production systems.

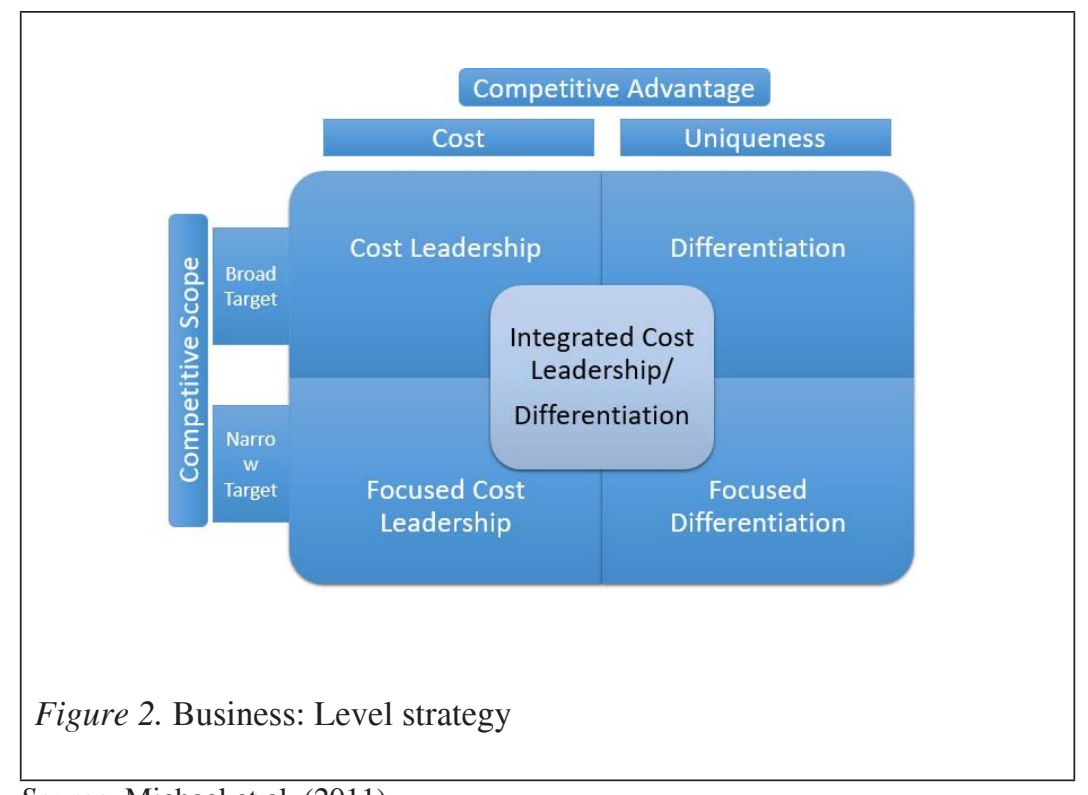

Source: Michael et al. (2011).

This strategy can match the customers' preference for batik products, which are the top five factors for batik pattern, price, product design, product quality and promotion. Furthermore, according to Al-Ekam et al (2012) in Al-Ekam (2016), in most of the developing countries the local brands tend to be less popular among the society due to the marketing factors which apparently have a crucial role in customers' purchase behaviour.

jBatik, currently without direct competitors, is the next product to be highlighted. The integrated cost management/differentiation strategy is the best strategy, just like Batik Fractal. As already stated, jBatik is a costeffective software, but it is rather unique. Piksel Indonesia continues to use local and near resources to develop $\mathrm{jBatik}$ because the low prices are currently gained. The software development team, however, has great creativity to support the software that differs from other software like Adobe or Corel.

Finally, Piksel Indonesia should adopt a better system of Total Quality Management (TQM) for further improvement. TQM is a managerial innovation that confirms total engagement of the company with the customers 
and constant improvement within the company throughout each process (Michael et al., 2011). This technique allows the company to improve consumer satisfaction with the product and service, accelerate market innovation, and reduce costs. For customers to buy batik products, batik pattern has one of the most important considerations thus, Piksel Indonesia can use its jBatik technology to distinguish or adjust its variation in batik patterns based on the customers' demand or trend. With the adoption of this sort of strategy, Piksel Indonesia can hopefully generate more revenue. The strategy also aligns with the first strategy. In addition, such an improvement might meet the quality factors of batik products preferred by customers such as batik design, product design, selected materials, prices, and colours.

As shared, the research presented in this paper was conducted by examining Piksel Indonesia's main business issues with the hope to have a more comprehensive business strategy. The mixed methods were used to obtain a whole information needed to form the strategy, based on the in-depth interviews with particular parties, and correlated with the SWOT and TOWS analysis. The questionnaire shows that the most preferred choice in the buying decision is the patterns of batik, followed by the the second largest mean which is the price, and the third one chosen is the product design. Moreover, Piksel Indonesia offers their company's differentiations in the social impact and technology advancements. Evidently, the respondents show their great interests on these two advantages. The integrated cost management/differentiation is the best business strategy for Piksel Indonesia. Furthermore, jBatik, currently without direct competitors, is the next product to be highlighted. The integrated cost management/differentiation strategy is the best strategy, as in the case of the Batik Fractal.

\section{References}

Al-Ekam, J. M. E. (2016). The mediating effect of brand trust on the influence of communication, price, and product quality on consumer purchase behaviour in a less-developed country. Malaysian Management Journal, 20, 87-97.

Bhattacharya, S., \& Anand, V. (2016). An empirical study on the factors affecting online retail brand engagement and purchase intention. Malaysian Management Journal, 20, 111-129.

Gurel, E., \& Tat, M. (2017). SWOT analysis: A theoretical review. The Journal of International Social Research, 10(51).

Hitt, M. A., Ireland, R. D., \& Hoskisson, R. E. (2011). Concepts strategic management competitiveness \& globalization (9th ed.). SouthWestern: CENGAGE Learning. 
Kapoor, S., \& Kaur, M. (2017). Basel III norms: A Swot and tows approach. Vision, 21(3), 250-258.

Kim, N. (2016). Local sport development strategy through sport development model and tows matrix. International Information Institute (Tokyo), 19(4), 1209-1214.

Kotler, P., \& Keller, K. (2016) Marketing management (15th ed.). Saddle River: Prentice Hall.

Madsen, D. O. (2016). SWOT Analysis: A management fashion perspective. International Journal of Business Research, 16(1), 39-56.

Mandey, N., \& Kawung, D. (2016). Purchased interests to establish of batik products in Manado, North Sulawesi. International Journal of Business and Management Invention, 5(10), 64-69.

Nugroho, O., \& Andadari, R. K. (2014). The innovation of micro, small, and medium enterprises: A case study of Laweyan Batik Village Indonesia. Indian Journal of Commerce and Management Studies, 5(2), 37-46.

Nurfikriyadi, (2016). Proposed marketing strategy for batik nation: A batik fashion startup company (Unpublished Master Thesis). School of Business Management. Institut Teknologi Bandung.

Nuryakin. (2018). Competitive advantage and product innovation: Key success of batik smes marketing performance in Indonesia. Academy of Strategic Management Journal, 17(2), 1-17.

Pesol, N. F., Mustapha, N. A., Ismail, S. S., \& Yusoff, N. M. (2016). The attributes of Malaysian batik towards tourist purchase decision. Tourism, Leisure and Global Change, 3, TOC-105.

Pinasti, M., \& Adawiyah, W. R. (2016). Co-opetition to promote growth of batik small and medium enterprises. International Journal of Business and Society, 17(3), 401-412.

Rahmawati, D., Rahadi, R. A., \& Damayanti, S. M. (2018). Business valuation for small medium enterprise: Case study: Piksel Indonesia. International Journal of Business, Economics and Law, 17(2), 9-15.

Sabijono, G. (2013). Analysis of Manado consumer preference in buying batik apparel product. Jurnal EMBA, 1(4), 414-421.

Salavou, H. E. (2015). Competitive strategies and their shift to the future. European Business Review, 27(1), 80-99.

Schmahl, K., \& Chen, C. (2017). An updated approach for depicting swot factors and strategic actions. Paper presented 38th International Annual Conference of the American Society for Engineering. Huntsville, Alabama, USA.

Sekaran, U., \& Bougie, R. (2016). Research methods for business: A skillbuilding approach (7th ed.). New Jersey: John Wiley \& Sons.

Tripes. S., Komarkova, L., Pirozek, P., \& Dvorak, J. (2014). Determinants of a successful differentiation strategy. European Conference on Management, Leadership \& Governance, 330-336. 